\title{
Interplay between Platelet Endothelial Cell Adhesion Molecule-1 and Pigment Epithelium-Derived Factor in Non-Small-Cell-Lung Cancer
}

\author{
Alexander Emmert ${ }^{1}$, Angelika Oellerich ${ }^{1}$, Laszlo Füzesi², Regina Waldmann-Beushausen ${ }^{1}$, \\ Friedrich A. Schöndube1, Hanibal Bohnenberger ${ }^{2}$, Bernhard C. Danner ${ }^{1}$ \\ ${ }^{1}$ Department of Thoracic and Cardiovascular Surgery, University Medical Center Göttingen, Göttingen, Germany \\ ${ }^{2}$ Institute of Pathology, University Medical Center Göttingen, Göttingen, Germany \\ Email: *alexander.emmert@med.uni-goettingen.de
}

How to cite this paper: Emmert, A., Oellerich, A., Füzesi, L., Waldmann-Beushausen, R., Schöndube, F.A., Bohnenberger, H. and Danner, B.C. (2016) Interplay between Platelet Endothelial Cell Adhesion Molecule-1 and Pigment Epithelium-Derived Factor in Non-Small-Cell-Lung Cancer. Open Journal of Thoracic Surgery, 6, 47-56.

http://dx.doi.org/10.4236/ojts.2016.64007

Received: September 27, 2016

Accepted: December 6, 2016

Published: December 9, 2016

Copyright $\odot 2016$ by authors and Scientific Research Publishing Inc. This work is licensed under the Creative Commons Attribution International License (CC BY 4.0).

http://creativecommons.org/licenses/by/4.0/

\section{Abstract}

Pigment epithelium-derived factor (PEDF), a potent antiangiogenesis agent, is a multifunctional protein with important roles in regulation of inflammation and angiogenesis. It has recently attracted attention for targeting tumor cells in several types of tumors. PECAM-1 is an integral membrane protein, a cell adhesion molecule with proangiogenic activity and plays an important role in the process of angiogenesis. The correlation between proangiogenic activity PECAM-1 and antiangiogenic activity PEDF in Non-Small-Cell-Lung Cancer has not been reported. The present study was designed to evaluate using immunohistochemical techniques and multivariate analysis the interplay between PECAM-1 and PEDF in NSCLC, especially in adenocarcinoma and in squamous cell carcinoma stage IA-IIIB. Analyzing the mixed study collectively $(n=69)$, there was no significant correlation $(p=0.553)$ between PECAM-1 signal and PEDF area. Only including patients with adenocarcinoma (Figure 2), we found a positive correlation between PECAM-1 signal and PEDF area $(\mathrm{p}=0.025)$. In patients with squamous cell carcinoma, we did not find a significant correlation between PECAM-1 signal and PEDF area $(\mathrm{p}=0.530)$. In patients with squamous cell carcinoma, PECAM-1 and PEDF show a significant different expression pattern, measured via staining intensity $(\mathrm{p}=0.013)$. These results might support the hypothesis that squamous cell carcinomas heavily rely on angiogenic processes.

\section{Keywords}

NSCLC, PEDF, PECAM-1, Neoangiogenesis 


\section{Introduction}

Non-small cell lung cancer (NSCLC) is a worldwide problem and the most lethal malignancy in many countries. The 5-year survival rate of resected NSCLC, however, ranges from only $25 \%$ to $73 \%$ depending on the pathological stage of the disease [1]. NSCLC is characterized by uncontrolled growth and spread of abnormal cells caused by tumor neoangiogenesis [2]. Neoangiogenesis describes the growth of new blood vessels, an important natural process with a complex control system at various physiological circumstances, but at the same time a critical factor during tumor development [3]. In recent years, therapies selectively targeting neoangiogenesis pathways, such as VEGFR have both provided a better understanding of NSCLC and have been investigated as prognostic factors or targets for individualized therapy but have not led to a significant therapy improvement [4] [5]. Therefore, it is important to understand the underlying molecular mechanism of neoangiogenesis in NSCLC. Intensity of neoangiogenesis in tumor is supposed to be reflected by intratumoral microvessel density (MVD). Numerous studies have measured tumor microvessel density (MVD) by PECAM-1 (Platelet Endothelial Cell Adhesion Molecule-1) staining. PECAM-1 is a $130-\mathrm{kDa}$ integral membrane protein, also known as CD31, a cell adhesion molecule with proangiogenic activity and plays an important role in the process of angiogenesis [4] [6].

Moreover, pigment epithelium-derived factor (PEDF), a $50-\mathrm{kDa}$ secreted endogenous glycoprotein, was first identified from human fetal retina pigment epithelium cell cultures as a member of the serine protease inhibitor superfamily with potent neurotropic activity [5]. However, more attention has been paid to its antiangiogenic activity [7]. The antivascular activity of PEDF appears to be associated with two main mechanisms: activation of Fas-FasL-mediated apoptosis and downregulation of vascular endothelial growth factor (VEGF) expression [8] [9] [10].

The correlation between proangiogenic activity of Platelet Endothelial Cell Adhesion Molecule-1 and antiangiogenic activity of Pigment Epithelium-Derived Factor in NonSmall-Cell-Lung Cancer has, to the best of our knowledge, not been reported. The present study was designed to evaluate using immunohistochemical techniques and multivariate analysis the interplay between PECAM-1 and PEDF in NSCLC, especially in adenocarcinoma and in squamous cell carcinoma stage IA-IIIB.

\section{Materials and Methods}

\subsection{Patient Inclusion and Tissue Samples}

A total of 42 consecutive patients with a stage IA-III squamous cell carcinoma (SCC) and 27 consecutive patients with a stage IA-III lung adenocarcinoma (ADC), who underwent radical surgical resection at the thoracic surgery department of the University Medical Center Goettingen between 2000 and 2007 were included in this retrospective study. The project was approved by the local ethical committee (\#1-2-08). Preoperative interdisciplinary tumor board meetings were held and proposed curative resection surgery for each patient included. No other previous or concomitant primary cancer was 
present. All procedures were conducted in accordance with institutional, state and federal guidelines.

WHO classification was used for histological assessment of each specimen and $\mathrm{Pa}$ thological staging of each tumor was determined using the renewed TNM staging system for NSCLC. Table 1 summarizes further clinical characteristics.

A structured follow up questionnaire was sent to oncologists, pulmonary physicians and general practitioners.

\subsection{Histological Evaluation of Microvessel Density}

Tumor tissues from each lung cancer specimen were fixed in $4 \%$ buffered formalin and embedded in paraffin. Immunohistochemical reactions were performed on $2 \mu \mathrm{m}$ tissue sections. Following deparaffinization and rehydration the sections were incubated in target Retrival Solution, $\mathrm{pH}$ low (Dako, Hamburg, Germany) for $40 \mathrm{~min}$ at $90^{\circ} \mathrm{C}$. Thereafter the samples were incubated for 15 min with $3 \% \mathrm{H}_{2} \mathrm{O}_{2}$ (Dako) to block endogenous

Table 1. Clinical characteristics of included lung cancer patients. Table one summarizes the clinic-pathologic characteristics of the patients included in this study.

\begin{tabular}{|c|c|c|}
\hline Characteristics & Adenocarcinoma $(\mathrm{n}=27)$ & Squamous cell carcinoma $(n=42)$ \\
\hline Age (years) & 63.18 & 65.85 \\
\hline \multirow{2}{*}{ Gender } & 20 male $(74.1 \%)$ & 41 male $(97.6 \%)$ \\
\hline & 7 female $(25.9 \%)$ & 1 female $(2.4 \%)$ \\
\hline \multirow{3}{*}{ Operation type } & Pneumectomy: 3 (11.1\%) & Pneumectomy: 10 (23.8\%) \\
\hline & Lobectomy: $22(81.5 \%)$ & Lobectomy: 27 (64.3\%) \\
\hline & Bilobectomy: 2 (7.4\%) & Bilobectomy: 5 (11.9\%) \\
\hline Lymphnodes resected (n) & $17.8 \pm 6.8$ & $20.9 \pm 8.6$ \\
\hline \multirow{6}{*}{$\begin{array}{l}\text { Pathologic Stage } \\
\text { (UICC 2010) }\end{array}$} & IA: $3(11.1 \%)$ & IA: $3(7.1 \%)$ \\
\hline & IB: $13(48.1 \%)$ & IB: $12(28.6 \%)$ \\
\hline & IIA: $1(3.7 \%)$ & IIA: $9(21.4 \%)$ \\
\hline & IIB: $4(14.8 \%)$ & IIB: $8(19.0 \%)$ \\
\hline & IIIA: $6(22.2 \%)$ & IIIA: $9(21.4 \%)$ \\
\hline & & IIIB: $1(2.4 \%)$ \\
\hline \multirow{6}{*}{$\mathrm{T}$ parameter } & T1a: 17 (18.5\%) & T1a: $3(7.1 \%)$ \\
\hline & T1b: $6(22.2 \%)$ & T1b: $7(16.7 \%)$ \\
\hline & T2a: $10(37.0 \%)$ & T2a: $13(31.0 \%)$ \\
\hline & T2b: $4(14.8 \%)$ & T2b: $9(21.4 \%)$ \\
\hline & T3: $2(7.4 \%)$ & T3: 7 (16.7\%) \\
\hline & & T4: $3(7.1 \%)$ \\
\hline \multirow{4}{*}{$\mathrm{N}$ parameter } & N0: $17(63 \%)$ & N0: $27(64.3 \%)$ \\
\hline & N1: $16(14.8 \%)$ & N1: $9(21.4 \%)$ \\
\hline & $\mathrm{N} 2: 6(22.2 \%)$ & N2: $5(11.9 \%)$ \\
\hline & & N3: $1(2.4 \%)$ \\
\hline \multirow{3}{*}{ Grading } & $1^{\circ}$ Grade: $1(3.7 \%)$ & \\
\hline & $2^{\circ}$ Grade: $17(63.0 \%)$ & $2^{\circ}$ Grade: $28(66.7 \%)$ \\
\hline & $3^{\circ}$ Grade: $9(33.3 \%)$ & $3^{\circ}$ Grade: $14(33.3 \%)$ \\
\hline Mean follow up time (month) & $35 \pm 27.9$ & $51.5 \pm 35.9$ \\
\hline
\end{tabular}


peroxidase activity. For primary antibodies the sections were incubated for overnight at $4^{\circ} \mathrm{C}$ temperature with the monoclonal antibody JC70A diluted at 1:30 (Dako). Thereafter the sections were incubated with a two-step indirect streptavidin-biotin secondary antibody system coupled to HRPO peroxidase (Dako). DAB (Dako) was applied to visualize the sites of immunoprecipitations. Tissue samples were analyzed by light microscopy after counterstaining with Meyer's haematoxylin.

Recommendations of Weidner were followed to assess MVD [11] [12]. Delineation of the stroma around living tumour tissue and cancer cells was provided by H\&E stained sections and only these regions were further analyzed. Two independent investigators determined hotspots with highest expression of PECAM-1 at a magnification of $\times 25$. Once hotspots were identified, PECAM-1 positive cells were counted at a magnification of $\times 100$. A total of 324 fields were analyzed (12 per patient).

\subsection{Evaluation of PEDF-Staining}

Regions of interest were determined by the hot spot method and detection of vital tumour tissue and cancer cells by the $\mathrm{H} \& \mathrm{E}$ stained sections. These regions were analyzed at a magnification of $\times 25$ by two separate investigators. Signal intensity was measured by semi quantitative scale $(1,1+, 2-, 2,2+, 3-, 3,3+)$ and median values were determined. As PEDF signalling appeared in spot like forms, a PEDF signalling area measurement was undertaken in $\mu \mathrm{m}^{2}$. A product of the intensity index and area of PEDF was calculated (Area-intensity index).

\subsection{Statistical Analysis}

Clinicopathologic standard parameters including gender, histopathology, UICC and pT stage, lymph node status and grading were analyzed with regard to the findings of immunohistochemistry. Categorical variables were expressed as proportions (\%) or number ( $\mathrm{n}$ ) and continuous variables as mean \pm standard deviation (SD) and median with range. Long-term follow-up (survival or lung cancer related death at 90 days after surgery) was determined by the Kaplan-Meier method, differences between groups were tested with the log rank test and Cox Regression $t$ influence of clinicopathologic parameters analysis was used. Association analysis for linear correlation of median PECAM-1 values was given as Pearson's correlation coefficient, whereas Kendall tau-b correlation coefficient $\mathrm{T}$ was provided for correlation with clinicopathologic parameters. Results were considered significant for $\mathrm{p}$ values below 0.05 . Long term follows up, defined as survival or death after 90 days postoperative could be fully completed. To test the influence of PECAM-1 expression on long-term survival, all patients with known lung cancer death or living were studied. Statistical modelling and testing were performed with SPSS ${ }^{\circledR}$ statistical software (Release 15.0.0).

\section{Results}

\subsection{ADC Group}

A total of 27 patients with available lung adenocarcinoma tumor tissue blocks were in- 
cluded in the analysis. Exclusion criteria were NSCLC stage IV and unrespectable tumor. In the cohort of ADC, median age 63.18 years, were more male $(n=20)$ than female $(n=7)$ patients. 16 patients had stage I disease, 5 patients had stage II (IIA $=1$, IIB $=4$ ) and 6 patients had stage IIIA. During a median follow-up of 48 months, patients were clinically evaluated and were referred for radiological assessment as per clinical indications. The socio-demographic and clinical characteristics of the patients are described in Table 1 . At the time of last follow-up 6 patients were alive (22\%). Overall median survival time was 45 month. Lung cancer related death occurred in 14 patients (66\%), and for other non-tumorous reasons in 7 patients (33\%).

\subsection{SCC Group}

A total of 42 patients were included in the squamous cell carcinoma tissue blocks analysis. The median age was 65.85 years. In the cohort of SCC were 41 male $(n=41)$ and 1 female patients $(n=1)$. In this group 16 patients had stage I, 15 patients had stage II $(\mathrm{IIA}=8, \mathrm{IIB}=7)$, and 11 patients had stage III (IIIA $=9$, IIIB $=1)$. The socio-demographic and clinical characteristics of the patients are described in Table 1. At the time of last follow-up 19 patients (45\%) were alive. Overall median survival time was 45 month. Lung cancer related death occurred in 18 patients (43\%), and for other nontumorous reasons in 5 patients (12\%).

\subsection{Histological Assessment of Microvessel Density and PEDF Staining}

After immunohistochemical staining of PECAM-1 in the tissue sections, the MVD was counted according to the recommendations of Weidner [11] [12]. For this purpose, two independent investigators first determined hotspots with highest expression of PECAM-1 at a magnification of $\times 25$ and then counted PECAM- 1 positive cells in a total of 828 fields (12 per patient) at a magnification of $\times 100$. In PEDF staining, the mean intensity of signaling was $2.18 \pm 0.50$ (median 2.22, range $1.1-3.2$ ). The mean PEDF area was $1012 \pm 1285 \mathrm{~mm}^{2}$ (median $682 \mathrm{~mm}^{2}$, range $0-4617 \mathrm{~mm}^{2}$ ), and the area intensity index was mean $2142 \pm 2731$, median 1437 (range 0 - 8601).

\subsection{Correlation of PECAM-1 Signal, PEDF Are, and PEDF Intensity}

To investigate the correlation between PECAM-1 signal and PEDF area, we compared the median PECAM-1 signal/tissue sample to median PEDF area. Total PEDF area was calculated from 6 individual images/tissue sample (25× magnification). PEDF signal was found in a patchy, irregular pattern. Subsequently, the median value of PECAM-1 signal and total PEDF area were correlated.

Analyzing the mixed study collective $(n=69)$, there was no significant correlation ( $p$ $=0.553$ ) between PECAM-1 signal and PEDF area (Figure 1). However, only including patients with adenocarcinoma (Figure 2) we found a positive correlation between PECAM-1 signal and PEDF area $(\mathrm{p}=0.025)$.

In patients with squamous cell carcinoma (Figure 3 ) we did not find a significant correlation between PECAM-1 signal and PEDF area $(\mathrm{p}=0.530)$. In patients with 


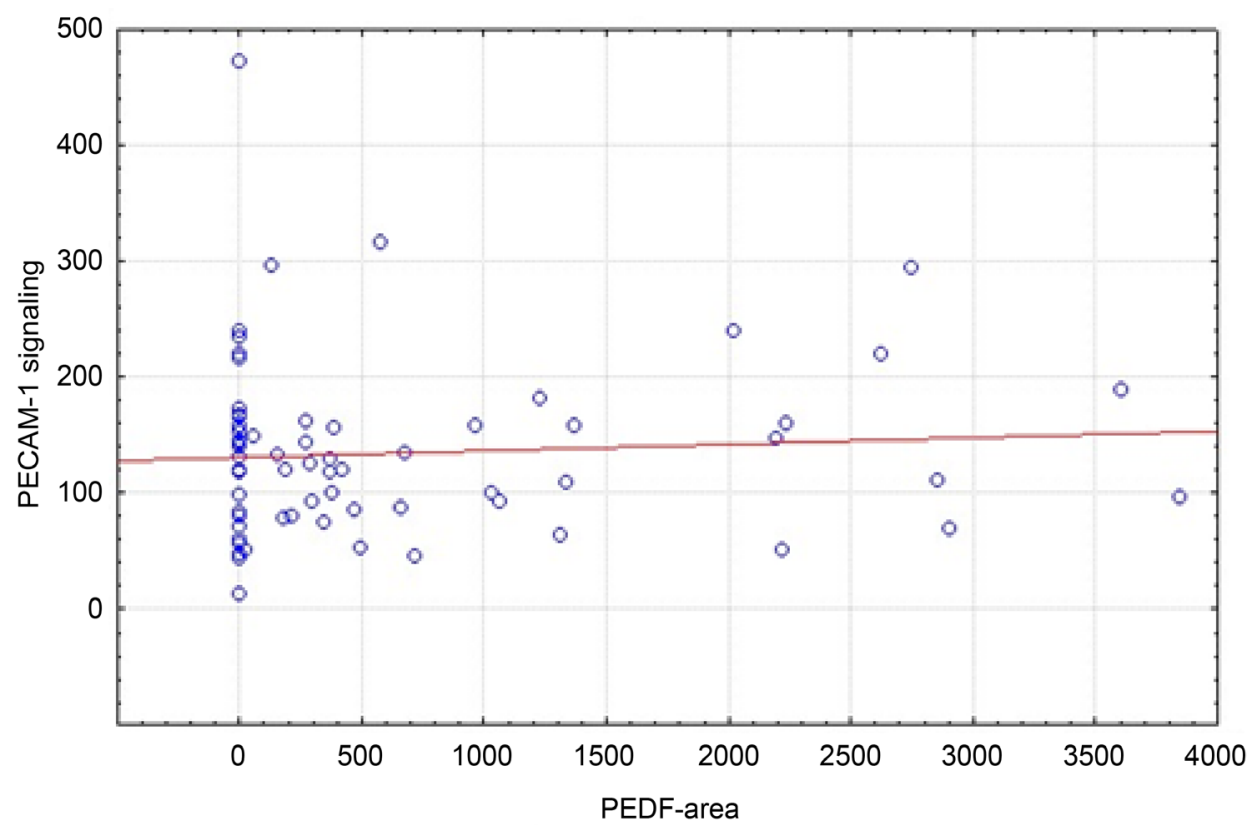

Figure 1. Correlation of median PECAM-1 signal and PEDF area $\left(\mu \mathrm{m}^{2}\right)$ of all patients independent of tumor histology $(n=68, r=0.0726 ; p=0.5533)$.

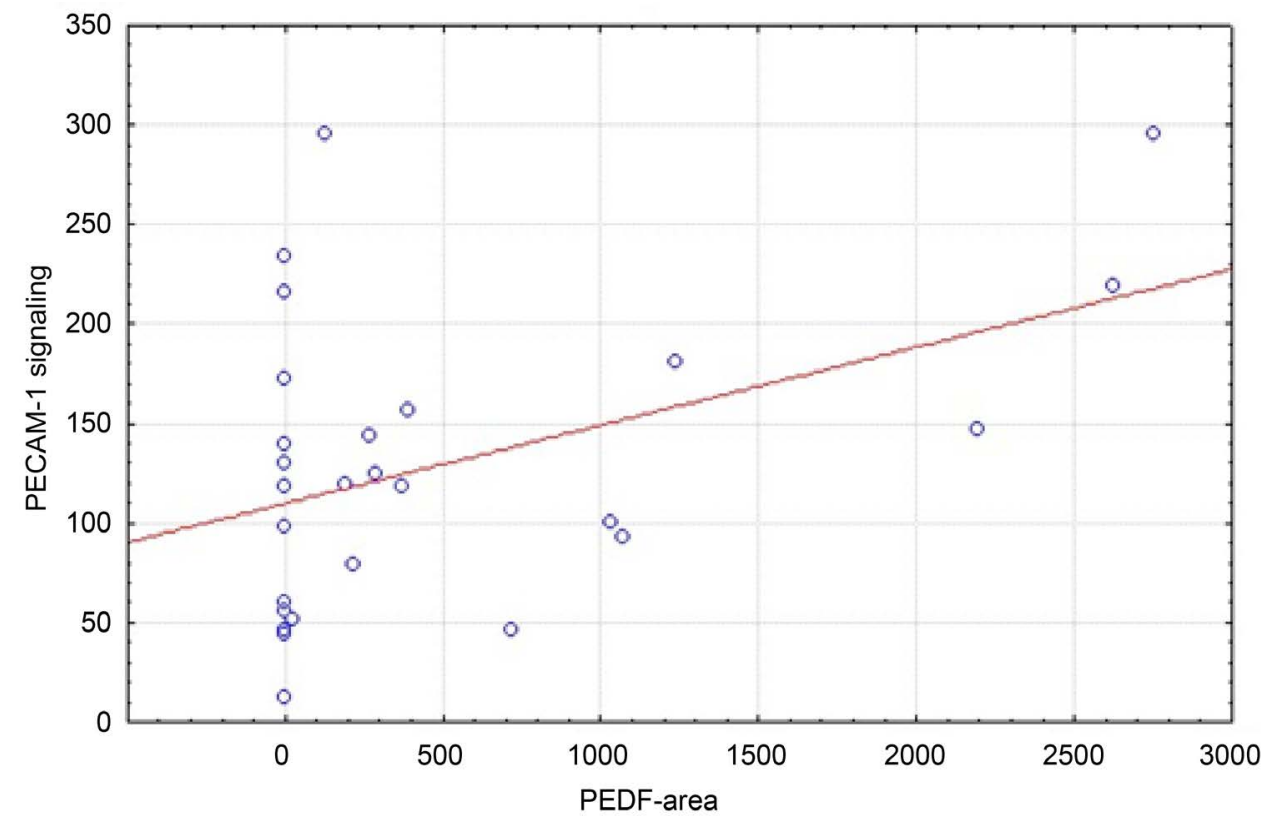

Figure 2. Correlation of median PECAM-1 signal and PEDF area $\left(\mu \mathrm{m}^{2}\right)$ in patients with adenocarcinoma $(\mathrm{n}=27, \mathrm{r}=0.4302 ; \mathrm{p}=0.0251)$.

squamous cell carcinoma PECAM-1 and PEDF show a significant different expression pattern, measured via staining intensity $(\mathrm{p}=0.013)$. Still, we could only find a trend towards a negative correlation with a generally low correlation coefficient $(-0.0661)$. Additionally, we found a significant correlation between CD31 signal and PEDF area in patients with adenocarcinoma (Figure 4). 


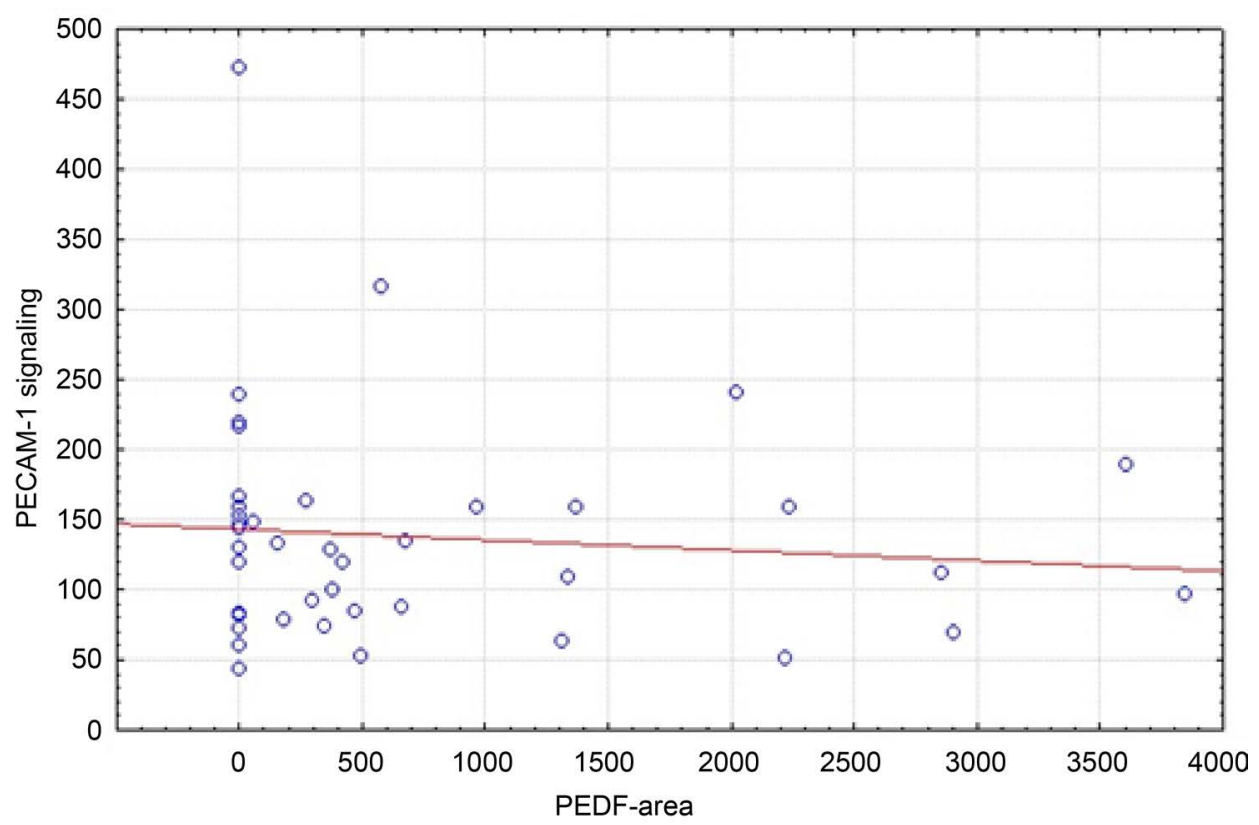

Figure 3. Correlation of median PECAM-1 signal and PEDF area $\left(\mu \mathrm{m}^{2}\right)$ in the squamous cell carcinoma patient cohort $(\mathrm{n}=41, \mathrm{r}=0.4302 ; \mathrm{p}=0.0251)$.

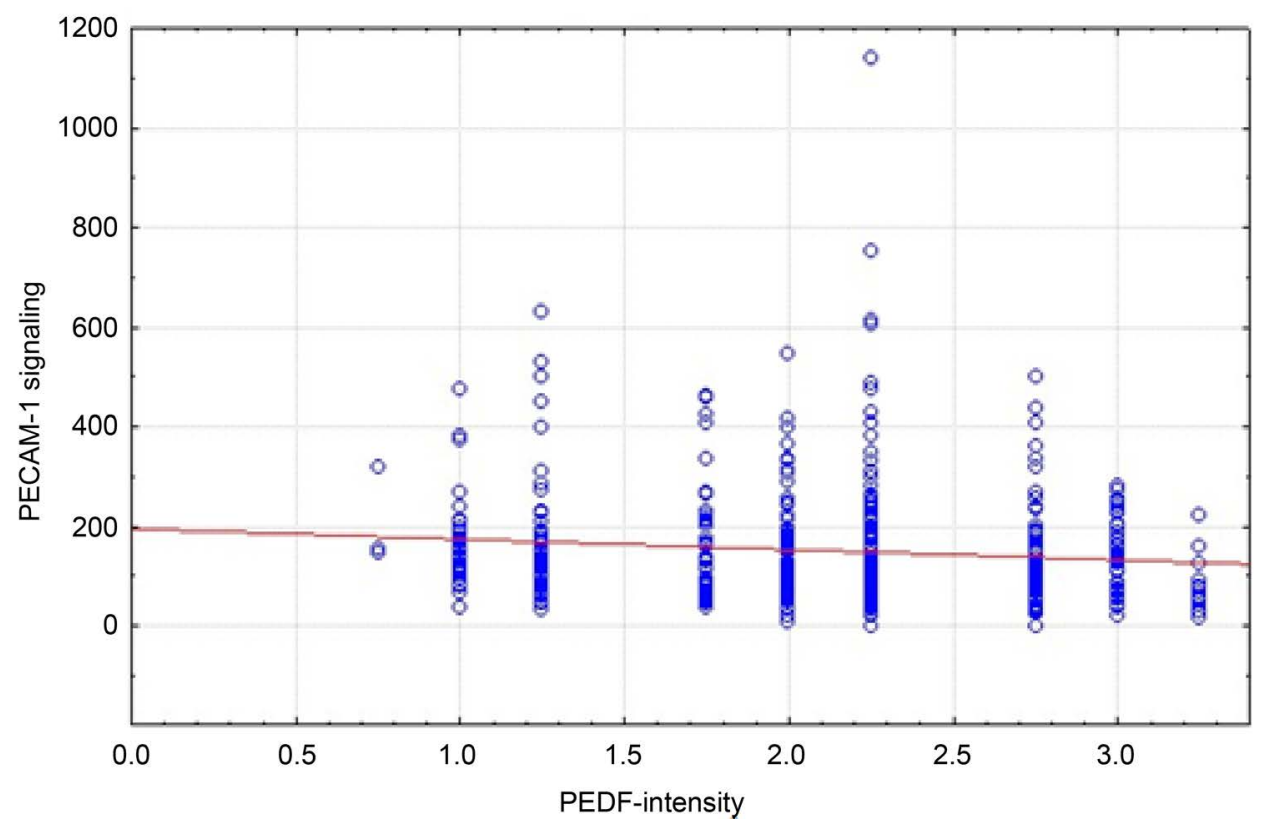

Figure 4. Correlation of median PECAM-1 signal and PEDF intensity in the squamous cell carcinoma patient cohort $(\mathrm{n}=41, \mathrm{r}=0.4302 ; \mathrm{p}=0.0251)$.

\section{Discussion}

The salient finding of the present study is the demonstration of interactions between of PECAM-1 and PEDF in patients with adenocarcinoma and squamous cell carcinoma of the lung. Neoangiogenesis is a complex phenomenon and solid tumors cannot grow beyond $1-2 \mathrm{~mm}$ in diameter without neoangiogenesis [13]. Therefore, it has been sug- 
gested that tumor neovascularization is a requirement for its growth [3].

According to current literature, PECAM-1 and PEDF have opposing functions in angiogenesis and were therefore chosen for further analyses. Especially in terms of endothelial cell proliferation, PECAM-1 and PEDF act in an antagonistic way: PECAM-1 seems to be a promotor of endothelial cell proliferation while PEDF acts as an inhibitor of endothelial cell proliferation.

In patients with squamous cell carcinoma PECAM-1 and PEDF show a significant different expression pattern, measured via staining intensity. Still, we could only find a trend towards a negative correlation with a generally low correlation coefficient. These results might support the hypothesis that squamous cell carcinomas heavily rely on angiogenic processes.

While we could not find a correlation between PECAM-1 signal and PEDF area when analyzing all patients independently of the specific tumor type or patients with squamous cell carcinoma, we could show that patients with adenocarcinoma of the lung have a positive correlation of PECAM-1 signal and PEDF area. Again, we see different signaling patterns in patients with squamous cell carcinoma and adenocarcinoma that might hint to diverging biological behavior.

\section{Conclusion}

In conclusion, the results of the present study suggest that PECAM- 1 and PEDF activity may account, at least in part, for the neoangiogenesis in NSCLC. The role of mediators such as fibroblast growth factor and VEGF in the vascularization of malignant entities has been well established, and the contribution of several other cytokines and growth factors has been suggested [14] [15]. The past few years have seen rapid development and improvement of tumor inhibitors, and an increasing body of evidence suggests that selective inhibitors of growth factors (e.g. EGFR) provide useful therapeutic agents, particularly in advanced NSCLC. Therefore, our current knowledge of neoangiogenesis and its role in distinct signaling pathways according to the organ has to be determined in future studies.

\section{Acknowledgements}

Hanibal Bohnenberger was supported by the Else-Kröner-Fresenius-Foundation.

We acknowledge support by the German Research Foundation and the Open Access Publication Funds of the Göttingen University.

\section{Competing Interests}

The authors declare that they have no competing interests.

\section{Contributions}

$\mathrm{AE}, \mathrm{BCD}, \mathrm{AO}$ and FAS conceived of the study and participated in its design. AO, AE, $\mathrm{HB}$ and FAS participated in the design of the study and performed the statistical analysis. $\mathrm{AO}, \mathrm{HB}$ and RWB participated in the interpretation of the pathologic data and crit- 
ical reviewing of the manuscript. $\mathrm{AE}, \mathrm{AO}$ and $\mathrm{BCD}$ drafted the manuscript. All authors read and approved the final manuscript.

\section{References}

[1] Goldstraw, P., Ball, D., Jett, J.R., Le Chevalier, T., Lim, E., Nicholson, A.G. and Shepherd, F.A. (2011) Non-Small-Cell Lung Cancer. Lancet, 378, 1727-1740. http://dx.doi.org/10.1016/S0140-6736(10)62101-0

[2] Hanahan, D. and Folkman, J. (1996) Patterns and Emerging Mechanisms of the Angiogenic Switch during Tumorigenesis. Cell, 86, 353-364. http://dx.doi.org/10.1016/S0092-8674(00)80108-7

[3] Folkman, J. (1989) What Is the Evidence That Tumors Are Angiogenesis Dependent? Journal of the National Cancer Institute, 82, 4-6. http://dx.doi.org/10.1093/jnci/82.1.4

[4] Pao, W. and Girard, N. (2011) New Driver Mutations in Non-Small-Cell Lung Cancer. Lancet Oncology, 12, 175-180. http://dx.doi.org/10.1016/S1470-2045(10)70087-5

[5] Fu, L., Shi, K., Wang, J., Chen, W., Shi, D., Tian, Y., Guo, W., Yu, W., Xiao, X., Kang, T., Wang, S., Huang, W. and Deng, W. (2014) TFAP2B Overexpression Contributes to Tumor Growth and a Poor Prognosis of Human Lung Adenocarcinoma through Modulation of ERK and VEGF/PEDF Signaling. Molecular Cancer, 13, 89.

http://dx.doi.org/10.1186/1476-4598-13-89

[6] DeLisser, H.M., Christofidou-Solomidou, M., Strieter, R.M., Burdick, M.D., Robinson, C.S., Wexler, R.S., Kerr, J.S., Garlanda, C., Merwin, J.R., Madri, J.A., et al. (1997) Involvement of Endothelial PECAM-1/CD31 in Angiogenesis. American Journal of Pathology, 151, 671677.

[7] Tombran-Tink, J. and Barnstable, C.J. (2003) PEDF: A Multifaceted Neurotrophic Factor. Nature Reviews Neuroscience, 4, 628-636. http://dx.doi.org/10.1038/nrn1176

[8] Dawson, D.W., Volpert, O.V., Gillis, P., Crawford, S.E., Xu, H., Benedict, W. and Bouck, N.P. (1999) Pigment Epithelium-Derived Factor: A Potent Inhibitor of Angiogenesis. Science, 285, 245-248. http://dx.doi.org/10.1126/science.285.5425.245

[9] Fernandez-Garcia, N.I., Volpert, O.V. and Jimenez, B. (2007) Pigment Epithelium-Derived Factor as a Multifunctional Antitumor Factor. Journal of Molecular Medicine (Berlin), 85, 15-22. http://dx.doi.org/10.1007/s00109-006-0111-z

[10] He, S.S., Wu, Q.J., Gong, C.Y., Luo, S.T., Zhang, S., Li, M., Lu, L., Wei, Y.Q. and Yang, L. (2014) Enhanced Efficacy of Combination Therapy with Adeno-Associated Virus-Delivered Pigment Epithelium-Derived Factor and Cisplatin in a Mouse Model of Lewis Lung Carcinoma. Molecular Medicine Reports, 9, 2069-2076.

[11] Weidner, N., Semple, J.P., Welch, W.R. and Folkman, J. (1991) Tumor Angiogenesis and Metastasis-Correlation in Invasive Breast Carcinoma. New England Journal of Medicine, 324, 1-8. http://dx.doi.org/10.1056/NEJM199101033240101

[12] Weidner, N., Carroll, P.R., Flax, J., Blumenfeld, W. and Folkman, J. (1993) Tumor Angiogenesis Correlates with Metastasis in Invasive Prostate Carcinoma. American Journal of Pathology, 143, 401-409.

[13] Chandrachud, L.M., Pendleton, N., Chisholm, D.M., Horan, M.A. and Schor, A.M. (1997) Relationship between Vascularity, Age and Survival in Non-Small-Cell Lung Cancer. British Journal of Cancer, 76, 1367-1375. http://dx.doi.org/10.1038/bjc.1997.562

[14] Dvorak, H.F., Lawrence, F.B., Detmar, M. and Dvorak, A. (1995) Vascular Permeability Factor/Vascular Endothelial Growth Factor, Microvascular Hyperpermeability, and Angi- 
ogenesis. American Journal of Pathology, 146, 1029-1039.

[15] Montrucchio, G., Sapino, A., Bussolati, B., Ghisolfi, G., Rizea-Savu, S., Silvestro, L., Lupia, E. and Camussi, G. (1998) Potential Angiogenic Role of Platelet-Activating Factor in $\mathrm{Hu}-$ man Breast Cancer. American Journal of Pathology, 153, 1589-1596.

http://dx.doi.org/10.1016/S0002-9440(10)65747-1

\section{Submit or recommend next manuscript to SCIRP and we will provide best service} for you:

Accepting pre-submission inquiries through Email, Facebook, LinkedIn, Twitter, etc.

A wide selection of journals (inclusive of 9 subjects, more than 200 journals)

Providing 24-hour high-quality service

User-friendly online submission system

Fair and swift peer-review system

Efficient typesetting and proofreading procedure

Display of the result of downloads and visits, as well as the number of cited articles

Maximum dissemination of your research work

Submit your manuscript at: http://papersubmission.scirp.org/

Or contact ojts@scirp.org 